\title{
EIGHTH INTERNATIONAL OTOLOGICAL CONGRESS, BUDA-PEST, 1909.
}

\section{Lenval Prize.}

Baron de Lenval, on the occasion of the Third International Otological Congress, founded a prize of 3000 francs to be awarded to such person as should invent and produce a small portable instrument very materially assisting the hearing of the deaf.

As no such instrument has yet been forthcoming to the satisfaction of the International Jury appointed to adjudicate upon the matter, the accumulated interest of four years, amounting to about 400 francs, will be awarded as a prize for the best work that has been published during the last four years in the departments of Anatomy, Physiology or Pathology of the Organ of Hearing.

Competing works should be sent to the President of the Jury, Prof. Dr. A. Politzer, I Gonzagagasse 19, Vienna, before the end of February, 1909.

The publication of the verdict of the Jury, and the presentation of the prize to the successful competitor, will take place at the Eighth International Congress, to be held at Buda-pest in August of this year.

The following gentlemen constitute the International Jury: Prof. Adam Politzer (President), Dr. Benni (Warsaw), Dr. Gellé (Paris), Prof. Urban Pritchard (London), Prof. Kirchner (Würzburg), Prof. Grazzi (Florence), Prof. Moure (Bordeaux), and Prof. Böke (Buda-pest).

\section{Abstracts.}

\section{PHARYNX.}

Hahn (Turin).-A New Method for the Treatment of Acute Follicular Tonsillitis. " Bollettino delle Malattie dell'Orecchio, etc.," No. 11, 1908.

The author defines the disease as an infective process, not specific, which often remains localised into the tonsils, but can easily overstep the barrier of this organ, and with the extension of infective and toxic products to other organs, produce localised disease in these organs, or general infection also.

He proves this assertion by numerous clinical facts collected from the publications of several authors.

In the presence of an infection that may cause, under favourable anatomical conditions, many and serious complications, it is reasonable to 
have recourse to a remedy more active than those usually indicated in treatises.

After mentioning what other laryngologists have proposed, the author proposes to wash the tonsillar crypts with a special syringe containing luke-warm oxygenated water (12 vol.) with a solution of boric acid ( 3 per cent.) This liquid is carefully injected into every crypta, and especially several times into the recessus of the palate and in the cavity situated behind the fold of His.

After having done this preparatory washing we must inject many times with the same method into the tonsillar crypts and the surrounding cavities, a lukewarm solution of novocaine of 2 or 3 per cent. in hydrochloride of adrenalin at 1 per cent., and then practise on the tonsil an insufflation of an anæsthetic powder.

The patient obtains an immediate improvement. Sometimes if the treatment is begun at the commencement of the illness the tonsillitis aborts. By freeing the crypts from their contents we are in the best condition to abridge the illness and to avoid the serious complications which may follow a follicular tonsillitis.

V. Grazzi.

Januskiewicz, A. M. (Kiew).-Pharyngitis Keratosa Punctata. "Virchow's Arch.," Bd. 193, Heft 1. Review by Babinsky in “ Arch. f. Kind.," Bd. 49, Heft 1 and 2.

In connection with a case of chronic benign mycosis of the tonsil, from which a piece was removed, it is shown that the cause of this affection is not so much the leptothrix found in these cases as a rodshaped bacillus described as $B$. keratosa, and somewhat resembling the diphtheria bacillus ; it is, however, thinner, and has a tendency to become curved. The bacillus was discovered and described by Wyssokowicz.

Alex. R. Tweedie.

Jovane, Antonio.-Spasm of the Isthmus Faucium in Children. "La Pediatria," February, 1907. Review by Neter (Mannheim) in "Arch. f. Kind.," Bd. 49, Heft. 1 and 2.

Three cases of dysphagia in children are described, and all only in respect of solids. All three children were deficient in intellect. One of the cases is reported:

A boy, aged one and a half years; parents blood relations; one brother with the same difficulty in swallowing; breast fed. Solid food was first returned at one year old, when the mother noticed he began to keep it a long time in his mouth, to chew it, and then spit it out. If he was compelled to swallow it, choking and eventually vomiting ensued. This story was corroborated in the clinic. Fluids were easily swallowed. At the age of three the dysphagia gradually disappeared. The child was well nourished but markedly rachitic; the palate is described as hyperæsthetic. He was an imbecile. Alex. R. Tweedie.

\section{NOSE.}

Lindt, Prof. (Berne).-A Rare Case of Tuberculosis of the Nose. "Archives Internationales de Laryngologie, d'Otologie, et de Rhinologie," September-October, 1908.

The author describes a case of a young man suffering from an inodorous, muco-purulent discharge of the right nostril. On examination a soft granulating swelling was discovered involving the posterior third of the inferior turbinate, which easily bled when touched by the probe. 